\title{
Introduction: A Social History of the Irish and British Mesolithic
}

\author{
Ben Elliott ${ }^{1} \cdot$ Aimée Little $^{1}$
}

Published online: 9 August 2018

(c) The Author(s) 2018

This Journal of World Prehistory special issue, A Social History of the Irish and British Mesolithic, brings together a generation of researchers working on the Mesolithic of Ireland and Britain in a series of collaborative papers. The impetus for this was the Mesolithic Britain and Ireland: 10 Years On session, held at the 2014 Theoretical Archaeology Group (TAG) conference in Manchester, UK, and chaired by Chantal Conneller and Graeme Warren. The aim of the session was to reflect on 10 years of research since a similar session in 2004, which led to the edited volume Mesolithic Britain and Ireland: New Approaches (Conneller and Warren 2006). Speakers were invited to consider the development of research within their field since 2004, and the direction that future work might take. Although originating from a range of analytical backgrounds, the contributors were united in having studied Mesolithic material through the course of their respective doctoral theses.

With such an eclectic range of specialisms we decided to bring together the authors in a series of collaborative pairings, allowing the exploration of common ground and shared interest, whilst placing their own work within the context of an alternative perspective. The papers within this special issue thus reflect elements of the original conference session, with an initial focus on the historiographic development of research themes, but also introduce new data and case studies through which novel ideas are presented. This format has created a series of papers which critically engage with established themes for prehistoric research, and develop approaches to these themes within the challenging context of the Mesolithic archaeological record-shaped by its own historiography, yet constantly being redefined with the development of new analytical approaches; at times fragmented and ephemeral, at times strikingly consistent and highly-resolved.

A number of themes emerge from these papers, which help to characterise the current state of play within Irish and British Mesolithic studies. These are time,

Ben Elliott

ben.elliott@york.ac.uk

Aimée Little

aimee.little@york.ac.uk

1 Department of Archaeology, University of York, King's Manor, Exhibition Square, York, UK 
chronology and organic remains, lithic technologies, humans in their environment, including relations with plants, animal and landscapes, identity in life and death, and a re-evaluation of ritual within the material record. Within the papers there are consistent calls to move beyond the critique offered by the post-processual movement within Mesolithic archaeology. This extends across the development of analytical methodologies, and the application of explicit bodies of theory, the influence of which has increased within prehistoric archaeology globally. Specifically, multiple papers highlight the need to bridge the growing divide between the fields of archaeological theory and archaeological science, and go on to outline methodological and theoretical means to overcome these challenges. Encouragingly, rather than simply calling for this movement, many of the papers demonstrate that it is already under way.

Another striking characteristic of the papers is the range of scales at which they address the Mesolithic archaeology of Britain and Ireland. All employ case studies, and the size and character of these datasets is notably diverse, ranging from individual moments and actions, identified through high-resolution analysis, to repeated patterns of behaviour observed at the site level, to landscape and regional discussions which synthesise large-scale units of time and space. As a collective, these papers work critically to apply different elements of social theory at a breadth of scales.

Whilst taking on this multi-scalar approach, almost all of the papers draw on ethnographic and anthropological data to support the arguments they build. It is interesting to note the developing disparity between the scales of analysis employed within these parallel discussions of archaeology and ethnography. Occasionally, we see patterns of human behaviours which play out over prolonged periods of time and large areas of space within the Mesolithic archaeological record, linked to individual instances of ethnographic observation, with little discussion of cultural context or the strength of these specific analogies. This tendency to link large-scale patterns with small-scale observations may stem from a fundamental tension which faces many forms of prehistoric archaeology: on the one hand, balancing the need to refer to the ethnographic record in order to see beyond the confines of our own cultural milieu, and on the other, attempting to understand past societies which, realistically, may share very few similarities with the (historically) narrowly bounded societies documented ethnographically. As such, we have a tendency to cherry-pick by highlighting specific examples of hunter-gatherer behaviour which help us to bridge the gap between emerging archaeological theory and the patterns identified through our analysis of the archaeological record. Some papers here acknowledge this, providing caveats within their arguments regarding the specificity of their analogies. However, this repeated disparity in scale between archaeological data and ethnographic analogy suggests that further attention is required to develop methodologies that engage more critically with the multi-scalar nature of contemporary hunter-gatherer studies.

Turning to the papers, Preston and Kador (2018) represents a collaboration between two researchers who have examined lithic technology within the Irish and English Mesolithic as part of their respective Ph.D.s. Kador's doctoral thesis (2007) took a critical approach to the concept of 'mobility' in the Irish Mesolithic, through an examination of stoneworking practices at the landscape level. This has been 
extended through post-doctoral research on the Movement and Migration in Irish Prehistory project, analysing stable isotope values derived from human remains at key points in Irish prehistory to study the patterns and variations in mobility. Preston's doctoral work (2011) centred on the analysis of lithic assemblages from across the Central Pennines, and investigated large-scale settlement patterns within this region. Their paper takes a historiographic approach to the development of huntergatherer mobility models within the context of Mesolithic Britain and Ireland, critically marking the development and influence of these ideas whilst outlining new themes and directions for future research.

Elliott and Griffiths (2018) take time and chronology as a chief concern, and explore this in relation to the growing record of organic material culture from Britain and Ireland. Griffiths' doctoral research (2011) modelled the Mesolithic-Neolithic transition in Britain from a chronological perspective, applying Bayesian modelling techniques to the corpus of radiocarbon dates available to plot in fine resolution the final use of microlith technologies and earliest adoption of agricultural practices. Elliott's thesis (2013) examined antler-based technologies throughout the British Mesolithic, taking a chaîne opératoire approach to link small-scale working actions to the broader relationship between people and deer during the period. Following the completion of his doctorate, Elliott has been involved in the analysis of bone and antler technological evidence from the recent excavations at Star Carr, North Yorkshire. Their paper tackles the multiple scales upon which Mesolithic chronologies operate, and seeks to critically address the implications of tensions between the micro and macro scale in the construction of Mesolithic narratives in Britain and Ireland.

Cobb and Gray Jones' collaboration focuses on human remains from Mesolithic Ireland and Britain, and represents a consideration of the concept of identity within the context of mortuary practices. Gray Jones' doctoral thesis (2011) involved the analysis of the so-called 'loose human bone phenomenon' across the Mesolithic of northwest Europe. Taking a chaîne opératoire approach to these disarticulated human remains, Gray Jones has demonstrated that a complex range of mortuary treatments was being applied during the period and played out over a larger spatial and temporal scale than had previously been realised. Cobb's Ph.D. (2008) examined the idea of Mesolithic experience, through a consideration of the Late Mesolithic and Early Neolithic land and seascapes of the northern region of the Irish Sea Basin. In exploring how the self is expressed in death, and in the treatment of human remains, Cobb and Gray Jones (2018) seek to explicitly engage with recent developments in assemblage theory to consider Mesolithic archaeology in a new light.

Overton and Taylor (2018) work together to address human interaction with animals and environments within the Irish and British Mesolithic. Overton's Ph.D. (2014) explored human and animal interactions in the Early Mesolithic of the Kennet Valley, England. Through the detailed study of faunal remains, their context of deposition, and the biology and behaviour of contemporary populations, Overton has argued for the development of nuanced and symmetrical relationships between animal and human populations at a landscape level. Taylor's (2012) doctoral thesis focussed on the relationship between the archaeological and palaeoenvironmental records of the Vale of Pickering, England, examining 
the fine-grained relationships between human actions and their environmental contexts. Their paper takes the Vale of Pickering as the setting for an exploration of human/animal interactions-developing rich narratives around zooarchaeological data to address the balance between human and animal agency within our understanding of Early Prehistoric sites.

Blinkhorn and Little's (2018) contribution works across a range of scales to address the concept of ritual within the Irish and British Mesolithic. This draws on Blinkhorn's (2012) doctoral research, which assessed the contribution of developerfunded archaeology to the understanding of the Mesolithic in England. It also combined Little's doctoral expertise in the Mesolithic of the Irish Midlands (2010). In working through elements of the archaeological record commonly considered to be 'mundane', Blinkhorn and Little develop an anthropologically informed framework for interpreting multi-scalar ritualised behaviours within ephemeral archaeological datasets.

Warren's (2018) assessment offers a longer-term perspective, from a co-organiser of the 2004 session, and someone who has a long history of Mesolithic research in Britain and Ireland. Having completed his Ph.D. on the social dynamics of the Scottish Mesolithic (2001), Warren worked extensively on the material elements of the Mesolithic and Early Neolithic in Ireland and Scotland. This has been contextualised within wider-reaching landscape projects, his involvement in which has granted an appreciation of the particularities of Mesolithic research in relation to other periods.

The papers presented in this special issue aim to define new approaches to our understanding of the Irish and British Mesolithic, marking developments in this field since the advent of the twenty-first century. The issue reflects the combined efforts of a new generation of researchers who have completed their doctorates within the past 10 years. A clear theme connecting all of these researchers is a desire and willingness to acknowledge and engage with the social aspects of hunter-gatherer life, alongside the more established concerns with economy, technology, chronology, death and burial, as well as broad-scale 'cultural identity'. The historiographic approach taken by many authors here demonstrates this clearly, and allows comparisons with approaches to the Mesolithic in other regions. Some of these concerns are shared, others are linked heavily to the academic culture specific to the study of Mesolithic Britain and Ireland.

Yet this issue has a wider significance, which extends beyond a set time and space. The challenges facing the study of the Irish and British Mesolithic are not unique within the field of prehistory globally, and share common ground with research on the Early Holocene, hunter-gatherer archaeology and materially ephemeral behaviours and practices (e.g. Beck and Jones 1997; Elston and Brantingham 2002; Goebel and Buvit 2011). As such, we hope that the papers presented here, and the case studies within them, will offer an opportunity for others to reflect critically on how these challenges may be overcome in other contexts. Furthermore, it is hoped that the historiographic theme which runs through the special issue will prompt readers to critically consider why a more socially-engaged understanding of prehistory is something for archaeologists to work towards. 
Acknowledgements The editors are indebted firstly to the organisers of the original TAG session, Drs. Chantal Conneller and Graeme Warren, for bringing this groups of researchers together. We also wish to thank the contributors for their willingness to work together in developing their ideas beyond the original single-author format of their conference papers. Finally, we wish to thank Tim Taylor, Sarah Wright, our two anonymous reviewers, and the Editorial Board of the Journal of World Prehistory for their support in bringing this special edition together.

Open Access This article is distributed under the terms of the Creative Commons Attribution 4.0 International License (http://creativecommons.org/licenses/by/4.0/), which permits unrestricted use, distribution, and reproduction in any medium, provided you give appropriate credit to the original author(s) and the source, provide a link to the Creative Commons license, and indicate if changes were made.

\section{References}

Beck, C., \& Jones, G. (1997). The Terminal Pleistocene/Early Holocene archaeology of the Great Basin. Journal of World Prehistory, 11(2), 161-236.

Blinkhorn, E. (2012). The Mesolithic and the planning process in England. Ph.D. thesis. York: University of York.

Blinkhorn, E., \& Little, A. (2018). Being ritual in Mesolithic Britain and Ireland: Identifying ritual behaviour within an ephemeral material record. Journal of World Prehistory. https://doi.org/10.1007/ s10963-018-9120-4 (this issue).

Cobb, H. (2008). Media for movement and making the world: An examination of the Mesolithic experience of the world and the Mesolithic to Neolithic transition in the Northern Irish Sea Basin. Ph.D. thesis. Manchester: University of Manchester.

Cobb, H., \& Gray Jones, A. (2018). Being Mesolithic in life and death. Journal of World Prehistory. https://doi.org/10.1007/s10963-018-9123-1(this issue).

Conneller, C., \& Warren, G. (2006). Mesolithic Britain and Ireland: New approaches. Stroud: Tempus.

Elliott, B. (2013). Antlerworking practices in Mesolithic Britain. Ph.D. thesis. York: University of York.

Elliott, B., \& Griffiths, S. (2018). Living Mesolithic time: Narratives, chronologies and organic material culture. Journal of World Prehistory. https://doi.org/10.1007/s10963-018-9119-x (this issue).

Elston, R., \& Brantingham, P. (2002). Microlithic technology in Northern Asia: A risk-minimizing strategy of the Late Paleolithic and Early Holocene. Archaeological Papers for the American Anthropological Association, 12(1), 103-116.

Goebel, T., \& Buvit, I. (Eds.). (2011). From the Yenesei to the Yukon: Interpreting lithic assemblage variability in Late Pleistocene/Early Holocene Beringia. College Station: Texas A\&M University Press.

Gray Jones, A. (2011). Dealing with the dead: Manipulation of the body in the mortuary practices of Mesolithic northwest Europe. Ph.D. thesis. Manchester: University of Manchester.

Griffiths, S. (2011). Chronological modelling of the Mesolithic-Neolithic transition in Britain. Cardiff: Cardiff University.

Kador, T. (2007). Marking out a new path: People, places and movement in early prehistoric Ireland. Ph.D. thesis. Dublin: University College Dublin.

Little, A. (2010). Tasks, temporalities and textures: Reconstructing the social topography of an Irish Mesolithic lakescape. Ph.D. thesis. Dublin: University College Dublin.

Overton, N. (2014). Memorable meetings in the Mesolithic: Tracing the biography of human-nonhuman relationships in the Kennet and Colne valleys with social zooarchaeology. Ph.D. thesis. Manchester: University of Manchester.

Overton, N. J., \& Taylor, B. (2018). Humans in the environment: Plants, animals and landscapes in Mesolithic Britain and Ireland. Journal of World Prehistory. https://doi.org/10.1007/s10963-018-9116-0 (this issue).

Preston, P. (2011). Lithics to landscapes: Hunter-gatherer tool use, resource exploitation and mobility during the Mesolithic of the Central Pennines, England. Ph.D. thesis. Oxford: Oxford University.

Preston, P. R., \& Kador, T. (2018). Approaches to interpreting Mesolithic mobility and settlement in Britain and Ireland. Journal of World Prehistory. https://doi.org/10.1007/s10963-018-9118-y (this issue). 
Taylor, B. (2012). The occupation of wetland landscapes during the British Mesolithic: Case studies from the Vale of Pickering. Ph.D. thesis. Manchester: University of Manchester.

Warren, G. (2001). Towards a social archaeology of the Mesolithic in eastern Scotland: Landscapes, contexts and experience. Ph.D. thesis. Edinburgh: University of Edinburgh.

Warren, G. (2018). From moments to histories: A social archaeology of the Mesolithic? Journal of World Prehistory. https://doi.org/10.1007/s10963-018-9121-3 (this issue). 